\title{
Illness Incidence, Psychological Characteristics, and Sleep in Dogsled Drivers During the Iditarod Trail Sled Dog Race
}

\author{
Magdalene C. Blakeson, $\mathrm{MSc}^{1}$; Scott P. Jerome, $\mathrm{PhD}^{2}$; Neil P. Walsh, $\mathrm{PhD}^{3}$; Erika Schagatay, $\mathrm{PhD}^{1,4}$; \\ Helen G. Hanstock, $\mathrm{PhD}^{1}$ \\ ${ }^{1}$ Swedish Winter Sports Research Centre, Department of Health Sciences, Mid Sweden University, Östersund, Sweden; ${ }^{2}$ Department of Chemistry \& \\ Biochemistry, University of Alaska Fairbanks, Fairbanks, Alaska; ${ }^{3}$ School of Sport and Exercise Sciences, Liverpool John Moores University, \\ Liverpool, UK; ${ }^{4}$ Environmental Physiology Group, Department of Health Sciences, Mid Sweden University, Östersund, Sweden
}

\begin{abstract}
Introduction-Every March, dogsled drivers (mushers) compete in a 1569-km race across Alaska, involving physical exertion, mental exertion, and sleep deprivation for up to $2 \mathrm{wk}$. These factors may increase mushers' vulnerability to illness, making them a relevant study population for acute infection risk factors. Specifically, the influence of psychological factors on illness risk during prolonged physical exertion has rarely been investigated. The aim of this study was to examine the relationship between psychological characteristics, sleep deprivation, and illness incidence in Iditarod mushers.

Methods-Fourteen mushers completed 4 psychological instruments to assess state and trait anxiety, resilience and perceived stress, and self-reported upper respiratory symptoms (URS) in the month before the race. Mushers self-reported sleep duration and URS during the race.

Results-State and trait anxiety, resilience, and perceived stress did not differ between mushers with and without pre- and in-race URS $(P>0.05)$. However, all mushers who reported in-race URS had reported URS $\leq 9 \mathrm{~d}$ before the race, and the onset of symptoms during the race typically occurred shortly after a rest period. Sleep duration was higher in mushers who reported in-race URS, both before $(4.9 \pm 0.3 \mathrm{~h}, P=0.016)$ and during illness $(5.9 \pm 1.3 \mathrm{~h}, P=0.006)$, vs mushers without in-race URS $(3.4 \pm 0.8 \mathrm{~h})$.

Conclusions-This study highlights recent illness, rest periods, and greater sleep requirements as potential risk factors for URS onset during a multiday endurance challenge, whereas psychological factors were not associated with URS.
\end{abstract}

Keywords: endurance, immunity, psychological stress, upper respiratory symptoms

\section{Introduction}

Prolonged physiological and psychological stress can negatively influence immune function. ${ }^{1}$ For athletes, military personnel, and others working in extreme environments, understanding risk factors for illness could help to prevent illness and facilitate performance and completion of essential training. Decrements in normal immune function and increased incidence of upper respiratory symptoms (URS) and gastrointestinal symptoms may arise as a result of prolonged training sessions,

Corresponding author: Helen G. Hanstock, PhD, Mid Sweden University, Swedish Winter Sports Research Centre, Studentplan 4, 83140 Östersund; e-mail: helen.hanstock@miun.se.

Submitted for publication May 2021.

Accepted for publication November 2021. exposure to extreme environments, inadequate nutrition, and disrupted sleep. ${ }^{1}$ Recently, the potential moderating effect of psychological factors, such as state anxiety and perceived stress, on immune responses to exercise has been highlighted. ${ }^{2}$ Continued research efforts are needed to understand how both physiological and psychological factors influence immune disturbances associated with physical stress.

Dogsled drivers, known as mushers, are a unique group of endurance athletes who compete in multiday races in extremely cold environments, undertaking heavy and prolonged physical exertion ${ }^{3}$ and forgoing normal sleep. ${ }^{4}$ These factors may contribute to an increased vulnerability to illness and thus makes this population an interesting model to study risk factors for common infections. In tandem, recommendations for performance 
Table 1. Overview of key variables and time point of collection

\begin{tabular}{|c|c|c|c|c|}
\hline Variable measured & Instrument used & Time point collected & $N$ & $M e a n \pm S D$ \\
\hline Trait anxiety & STAI-Y2 ${ }^{6}$ & 1 mo before race start & 10 & $34 \pm 6$ \\
\hline Resilience & $\mathrm{BRS}^{7}$ & 1 mo before race start & 10 & $3.8 \pm 0.6$ \\
\hline State anxiety & STAI-Y $1^{6}$ & Day before the race start & 11 & $40 \pm 11$ \\
\hline Perceived stress & PSS- $14^{8}$ & Day before the race start & 9 & $27 \pm 4$ \\
\hline $\begin{array}{l}\text { URS in month } \\
\text { before race }\end{array}$ & $\begin{array}{l}\text { Modified } \\
\text { JCCQ }^{9}\end{array}$ & Day before the race start & $\begin{array}{l}\text { Yes: } 6 \\
\text { No: } 6\end{array}$ & $\begin{array}{l}\text { Yes: Symptom score }=6.5 \pm 5.2 \text {, } \\
\text { duration }=4 \pm 1 \mathrm{~d}\end{array}$ \\
\hline $\begin{array}{l}\text { Sleep in month } \\
\text { before race }\end{array}$ & $\begin{array}{l}\text { Estimated } \\
\text { sleep duration }\end{array}$ & Day before the race start & 12 & $6.3 \pm 1.2 \mathrm{~h}$ \\
\hline URS during race & $\begin{array}{l}\text { Common cold } \\
\text { symptoms? } \\
\text { (yes/no) }\end{array}$ & Daily during race & $\begin{array}{l}\text { Yes: } 3 \\
\text { No: } 7\end{array}$ & Yes: Duration range $=2-6 \mathrm{~d}$ \\
\hline $\begin{array}{l}\text { Gastrointestinal } \\
\text { symptoms } \\
\text { during race }\end{array}$ & $\begin{array}{l}\text { Upset stomach? } \\
\text { (yes/no) }\end{array}$ & Daily during race & $\begin{array}{l}\text { Yes: } 0 \\
\text { No: } 10\end{array}$ & \\
\hline $\begin{array}{l}\text { Sleep duration } \\
\text { during race }\end{array}$ & $\begin{array}{l}\text { Hours of sleep, } \\
\text { reported to } \\
\text { nearest half } \\
\text { hour }\end{array}$ & Daily during race & 10 & $3.9 \pm 1.2 \mathrm{~h}$ \\
\hline $\begin{array}{c}\text { Environmental } \\
\text { temperature } \\
\text { during race }\end{array}$ & $\begin{array}{l}\text { Sensor attached } \\
\text { to sled }\end{array}$ & $\begin{array}{l}\text { Continuously during race } \\
\text { (rests excluded) }\end{array}$ & 4 & $\begin{array}{l}\text { Mean: }-7.6 \pm 3.5^{\circ} \mathrm{C} \\
\text { Min: }-39.4 \pm 1.0^{\circ} \mathrm{C} \\
\text { Max: } 10.5 \pm 7.0^{\circ} \mathrm{C}\end{array}$ \\
\hline
\end{tabular}

Data are reported as mean \pm SD unless otherwise stated. $\mathrm{N}$ refers to number of participants with complete data on a given variable.

optimization could benefit the sled dog racing community. Previous studies have typically focused on the occurrence of illness after endurance challenges. ${ }^{5}$ However, during multiday dogsled races, it is likely that illness may occur during the race, which may affect mushers' ability to remain alert to the needs of their dogs and stay competitive in the race.

The Iditarod is one of the best-known long-distance sled dog races, traversing $1569 \mathrm{~km}$ across interior Alaska. Mushers and their dog teams typically complete the course in 9 to $14 \mathrm{~d},{ }^{3}$ resting as needed at checkpoints every 30 to $130 \mathrm{~km}$. Mushers must take one 24-h and two 8-h breaks during the race at checkpoints of their choosing. On arrival at a checkpoint, mushers' first priority is to take care of the dogs. The musher then attends to personal needs and may manage to sleep for a few hours before departure on the next segment. ${ }^{3}$ The physical and psychological demands of traversing the trail combined with the responsibility to take care of the dogs means that fatigue and sleep deprivation are almost inevitable during the event. This setting provides an opportunity to investigate the influence of psychological factors on the ability to remain healthy during a multiday wilderness race involving multiple environmental, psychological, and physical stressors.

The main aim of this study was to investigate the influence of state and trait psychological characteristics and sleep quantity on the incidence of URS among competitors in the Iditarod sled dog race.

\section{Methods}

All 57 mushers who started the 2020 Iditarod were invited to participate in the study via email from the organizing committee. Participants contacted the research team for further information and provided informed consent to participate. The study was approved by the University of Alaska Fairbanks institutional review board and was conducted in accordance with the Declaration of Helsinki. The study employed a prospective cohort study design, where participants completed questionnaires before, during, and after the race. The main outcome measures were URS incidence before and during the race; participants were classified into groups based on these variables.

One month before the race, participants completed 2 questionnaires pertaining to trait psychological characteristics, intrinsic aspects of one's character that are relatively stable over time. These measurements included the trait aspect of the state-trait anxiety inventory (STAIY2) to measure trait anxiety, defined as a general tendency to perceive situations as threatening, ${ }^{6}$ and the brief resilience scale, which measures resilience, or the ability 
Table 2. State and trait psychological characteristics in mushers who reported pre-race and in-race upper respiratory symptoms (URS) versus those who remained symptom-free (healthy)

\begin{tabular}{|c|c|c|c|c|c|c|}
\hline \multirow[t]{2}{*}{ Variable: scale (score range) } & \multicolumn{3}{|c|}{ Pre-race } & \multicolumn{3}{|c|}{ In-race } \\
\hline & $\begin{array}{l}U R S \\
\text { Mean } \pm S D(n)\end{array}$ & $\begin{array}{l}\text { Healthy } \\
\text { Mean } \pm S D(n)\end{array}$ & $P$ & $\begin{array}{l}U R S \\
M e a n \pm S D(n)\end{array}$ & $\begin{array}{l}\text { Healthy } \\
\text { Mean } \pm S D(n)\end{array}$ & $P$ \\
\hline State anxiety: STAI-Y1 (20-80) & $43 \pm 12(6)$ & $36 \pm 8(5)$ & 0.29 & $47 \pm 16(3)$ & $40 \pm 5(6)$ & 0.54 \\
\hline Perceived stress: PSS (0-56) & $27 \pm 4(4)$ & $27 \pm 4(5)$ & 0.88 & $27 \pm 5(3)$ & $27 \pm 3(4)$ & 0.86 \\
\hline Trait anxiety: STAI-Y2 (20-80) & $32 \pm 6(5)$ & $35 \pm 7(5)$ & 0.53 & $28 \pm 6(2)$ & $36 \pm 6(6)$ & 0.18 \\
\hline Resilience: BRS (1.00-5.00) & $3.90 \pm 0.65(5)$ & $3.67 \pm 0.52(5)$ & 0.55 & $4.42 \pm 0.83(2)$ & $3.64 \pm 0.47(6)$ & 0.13 \\
\hline
\end{tabular}

to recover or bounce back after stress. ${ }^{7}$ The day before the race start, participants completed 3 further questionnaires. Two instruments were used to assess pre-race state characteristics, or transient emotional states usually caused by external factors, after participants had arrived at the race start. The state aspect of the STAI (STAI-Y1) was used to assess state anxiety, transient anxiety experienced in a specific situation. ${ }^{6}$ Perceived psychological stress was assessed using the 14-item perceived stress scale, which reflects the degree to which life situations were considered stressful by the mushers in the month leading up to the race. ${ }^{8}$ Mushers then completed a modified version of the Jackson common cold questionnaire. ${ }^{9}$ The first question asked whether the respondent had experienced a common cold in the past month. If the respondent answered yes, they were asked when the illness began, how many days it lasted, and to rate the severity of 8 symptoms (headache, sneezing, chilliness, sore throat, nasal discharge, nasal obstruction, malaise, and cough) on a 4 -point scale $(0=$ not at all; $1=$ mild; $2=$ moderate; $3=$ severe). Respondents who answered yes to the first question were categorized as having pre-race URS. Mushers were also asked to estimate their "average" sleep duration during the past month.

Participants carried a booklet on the trail that included daily questions regarding hours of sleep per $24 \mathrm{~h}$, whether they thought they were suffering from a common cold that day (yes/no) or had an upset stomach (yes/no), and space for comments. Mushers answered these questions once every $24 \mathrm{~h}$. Selected participants also carried a temperature logger (Thermochron 22L, iButton Link, Whitewater, WI), hung from the sled, that logged environmental temperature every $5 \mathrm{~min}$ throughout the race. Owing to last-minute COVID-19 restrictions at the finish line, mushers were requested to mail booklets and temperature loggers back to the research team; 10 of 14 booklets and 4 of 5 loggers were returned.

Mushers were categorized based on whether they reported pre-race and/or in-race URS. However, low participant numbers in the cohort and subgroups
(Table 1) led to an a posteriori decision to report only descriptive statistics (mean \pm SD unless otherwise stated) and unpaired $t$-test results of differences between groups that did and did not report URS. Thus, no models to predict illness risk were constructed. Significance was accepted at $P=0.05$.

\section{Results}

The 2020 Iditarod race traversed Alaska via the $1569 \mathrm{~km}$ Northern route. Only 34 of 57 teams finished-the highest drop-out rate since 1974. Fourteen mushers provided informed consent to participate (10 male, 4 female, aged $39 \pm 11$ y). Five participants were competing in the race for the first time, whereas others were experienced veterans. Seven participants completed the race in 9 to $14 \mathrm{~d}$. Five participants dropped out owing to illness among the dogs, 1 was pulled from the race, and 1 dropped out owing to illness. On the trail, participants faced temperatures from -39.4 to $10.5^{\circ} \mathrm{C}$ (Table 1 ). We had limited success in obtaining complete data sets from all participants (Table 1).

Five male mushers and 1 female musher reported prerace URS (Table 1). Five cases of URS presented 5 to 9 $\mathrm{d}$ before the race start, and 1 musher had ongoing URS at the race start.

Nine mushers completed the pre-race Jackson common cold questionnaire before the race start and returned data at the end of the race. Five remained healthy both pre-race and in-race. Of the 4 mushers who reported URS beforehand, 3 also reported URS during the race. Two episodes of URS occurred within $24 \mathrm{~h}$ after the compulsory 24-h break. One episode of URS occurred around the race finish. URS duration ranged from 2 to $6 \mathrm{~d}$. Comments regarding URS that arose during the race mentioned "cough" ( $(n=3)$, "sore throat" $(n=1)$, "shortness of breath" $(n=1)$, and "low energy" $(n=3)$. Other mushers who did not self-report URS nevertheless reported "low energy" $(n=2)$, "cough" $(n=1)$, and "headache" $(n=1)$ on occasion 


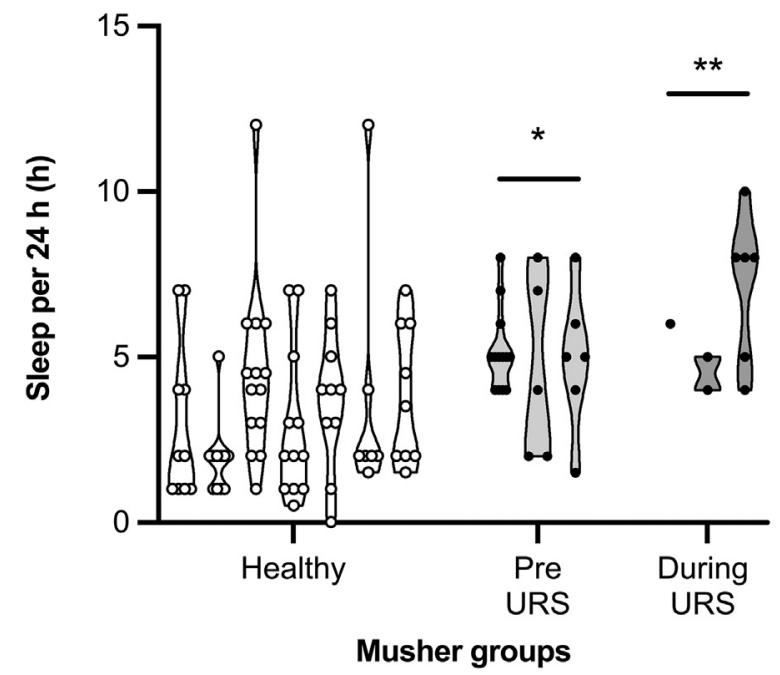

Figure 1. Sleep duration per 24-h period during the race. Individual violins represent nights of sleep for healthy mushers (white) and mushers with upper respiratory symptoms (URS) (gray), minimum to maximum. Individual dots represent individual 24-h periods during the race. The URS group is further divided into pre- and during-URS periods. Post-URS sleep data are not shown because only 1 participant's URS resolved before the race finish. Significant differences between URS and healthy group indicated: $* P<0.05 ; * * P<0.01$.

( 1 entry in all cases). No participants reported gastrointestinal illnesses during the race.

There were no significant differences in state (STAI-Y1 and perceived stress scale) and trait (STAI-Y2 and brief resilience scale) characteristics between mushers with or without URS either before or during the race (Table 2).

Sleep duration during the race was lower than that before the race $(P<0.01$; Table 1$)$. Mushers without URS slept less than mushers with URS both before $(3.4 \pm 0.8 \mathrm{vs}$ $4.9 \pm 0.3 \mathrm{~h}, P=0.016)$ and during $(3.4 \pm 0.8$ vs $5.9 \pm 1.3 \mathrm{~h}$, $P=0.006$ ) symptom onset (Figure 1 ).

\section{Discussion}

Field studies such as this provide insight into the demands of multiday wilderness races. ${ }^{3,4}$ With a mean of only $3.9 \mathrm{~h}$ sleep per $24 \mathrm{~h}$, our participants experienced sleep deprivation and environmental temperatures as low as $-39.4^{\circ} \mathrm{C}$. Illness was frequent both before and during the race, with half of the participants reporting URS before the race, 3 of 10 during the race, and one-off comments that could indicate illness reported by 3 further mushers during the race. We observed no significant differences in state anxiety, resilience, trait anxiety, or perceived stress between participants who self-reported illness before or during the race and participants who remained healthy. Sleep deprivation was more common among participants who remained healthy during the race and may have facilitated faster finishing times; the 2 fastest finishers among our cohort did not report URS either before or during the race.

The month before Iditarod involves numerous potential stressors for mushers, including selecting their dog team, training, developing their race plan, and traveling, often long distances, to the race start. Recent studies demonstrate that risk factors for developing URS include intensified training, long-haul travel, low energy availability, psychological stress, and depression. ${ }^{1,10}$ Such risk factors could perhaps explain why half of our participants experienced URS in the month before the race. Unsurprisingly, the mean state anxiety was considered moderate $^{11}$ and perceived stress was higher than normative values $^{12}$ in the days before the race.

That all of the mushers who experienced in-race illness had also experienced illness in the month leading up to the race was an interesting observation, and prerace illness was associated with in-race URS in 3 of 4 pre-race cases. We could speculate that in-race symptoms may have occurred via recurrence of symptoms from a pre-race common cold virus, given that participants likely had relatively little exposure to novel pathogens during the race, especially with COVID-19 restrictions. Nevertheless, during rests, participants could have been exposed to other mushers, volunteers, and locals who could be pathogen carriers, and mushers may have opted to rest after particularly arduous race segments. Of particular interest is the observation that mushers who experienced in-race illness in most cases developed URS symptoms shortly after their required 24-h break or after finishing the race. This may coincide with the classical post-exercise "open window" for opportunistic infections, whereby immune function is proposed to be temporarily compromised for a few hours after strenuous exercise. ${ }^{13,14}$ Similarly, we could draw parallels with the phenomenon termed "leisure sickness," in which illness often strikes during weekends and vacations, times generally associated with relaxation, the mechanisms of which remain unclear. ${ }^{15}$

One previous study investigated sleep deprivation in mushers during Europe's longest sled dog race and similarly found that participants typically slept for 3 to 4 $\mathrm{h} \cdot \mathrm{d}^{-1}{ }^{4}$ Although chronic sleep deprivation is known to negatively affect immune function, ${ }^{16}$ in the present study, mushers who remained healthy obtained less sleep than mushers with in-race URS, also before URS onset. One explanation may be that mushers who subsequently developed URS increased their sleep duration during the incubation period, which for a common cold is typically 2 to $5 \mathrm{~d} .{ }^{17}$ However, given that the mushers with in-race URS had also been ill before the race, the increased sleep may also be a lingering effect of prior illness. 


\section{LIMITATIONS}

As is typical for studies performed in a remote field setting and competition environment, we encountered challenges in the design and execution of this study that limit the scientific rigor and conclusions that can be drawn. First, participant recruitment and retention was poorer than expected, and many participants returned incomplete datasets. This prevented us from making predictive inferences about the association between psychological traits and illness risk. Second, there are limitations with self-reported estimates of sleep duration. Objective monitoring of sleep would have strengthened these data.

We must also be cautious in interpreting symptom data, in particular during the race, because there was overlap in the symptoms noted in the comments between mushers who did and did not self-report illness using the yes/no question. Symptoms such as "shortness of breath" and "cough" could have arisen for reasons other than a common cold, such as cold exposure causing irritation to the upper respiratory $\operatorname{tract}^{18}$; likewise, "low energy" could have resulted from sleep deprivation or illness.

Because we did not collect biological samples, we cannot identify specific pathogens that could have explained the symptoms reported. Thus, we cannot assume that the symptoms were of infectious origin (hence, we also do not know if any illness could have been COVID19). In addition, inclusion of other biological sampling procedures, such as measurement of salivary IgA, plasma cytokine, or leukocyte responses, would have enabled us to draw conclusions regarding biological responses to the stressors faced by participants during the race.

\section{Conclusions}

Our study highlights prior recent illness, rest periods, and greater sleep requirements as potential risk factors for symptom onset during a multiday wilderness event. State and trait psychological characteristics did not differ between mushers with and without illness. Future studies may wish to build on the present observations to elucidate critical time points for prevention of in-race illness during multiday endurance challenges and further assess the association between psychological factors, sleep, and illness risk in larger cohorts.

Acknowledgments: Thanks to the participants and to the Iditarod Trail Committee for supporting the study.

Author Contributions: Study concept and design (all authors); data acquisition (MCB); data analysis (MCB, HGH); drafting of the manuscript (MCB, HGH); critical revision of the manuscript and approval of final manuscript (all authors).

Financial/Material Support: HGH received a travel grant from Mid Sweden University via the University of the Arctic North2North program to support collaboration with the University of Alaska Fairbanks.

Disclosures: None.

\section{References}

1. Walsh NP. Recommendations to maintain immune health in athletes. Eur J Sport Sci. 2018;18(6):820-31.

2. Edwards JP, Walsh NP, Diment PC, Roberts R. Anxiety and perceived psychological stress play an important role in the immune response after exercise. Exerc Immunol Rev. 2018;24:26-34.

3. Cox C, Gaskill S, Ruby B, Uhlig S. Case study of training, fitness, and nourishment of a dog driver during the Iditarod 1049mile dogsled race. Int J Sport Nutr Exerc Metab. 2003;13 (3):286-93.

4. Calogiuri G, Rossi A, Formenti D, Weydahl A. Sleep recovery in participants after racing in the Finnmarkslop - Europe's longest dog-sled race. J Sports Med Phys Fitness. 2017;57(1-2):103-10.

5. Henson D, Nieman D, Davis JM, Dumke C, Gross S, Murphy A, et al. Post-160-km race illness rates and decreases in granulocyte respiratory burst and salivary IgA output are not countered by quercetin ingestion. Int J Sports Med. 2008;29(10):856-63.

6. Spielberger C. Manual for the State-Trait Anxiety Inventory. Palo Alto, CA: Mind Garden; 1983.

7. Smith BW, Dalen J, Wiggins K, Tooley E, Christopher P, Bernard J. The brief resilience scale: assessing the ability to bounce back. Int J Behav Med. 2008;15(3):194-200.

8. Cohen S, Kamarck T, Mermelstein R. A global measure of perceived stress. J Health Soc Behav. 1983;24(4):385-96.

9. Jackson GG, Dowling HF, Spiesman IG, Boand AV. Transmission of the common cold to volunteers under controlled conditions. I The common cold as a clinical entity. AMA Arch Intern Med. 1958;101(2):267-78.

10. Svendsen IS, Taylor IM, Tønnessen E, Bahr R, Gleeson M. Training-related and competition-related risk factors for respiratory tract and gastrointestinal infections in elite cross-country skiers. $\mathrm{Br}$ J Sports Med. 2016;50(13):809-15.

11. Barnes LLB, Harp D, Jung WS. Reliability generalization of scores on the Spielberger State-Trait Anxiety Inventory. Educ Psychol Meas. 2002;62(4):603-18.

12. Cohen S, Williamson G. Perceived stress in a probability sample of the United States. Soc Psychol Heal. 1988;13:31-67.

13. Nieman DC. Risk of upper respiratory tract infection in athletes: an epidemiologic and immunologic perspective. J Athl Train. 1997;32(4):344-9.

14. Walsh NP, Gleeson M, Shephard RJ, Gleeson M, Woods JA, Bishop NC, et al. Position statement. Part one: immune function and exercise. Exerc Immunol Rev. 2011;17:6-63.

15. Van Heck GL, Vingerhoets AJJM. Leisure sickness: a biopsychosocial perspective. Psychol Top. 2007;16(2):187-200.

16. Faraut B, Boudjeltia KZ, Vanhamme L, Kerkhofs M. Immune, inflammatory and cardiovascular consequences of sleep restriction and recovery. Sleep Med Rev. 2012;16(2):137-49.

17. Lessler J, Reich NG, Brookmeyer R, Perl TM, Nelson KE, Cummings DAT. Incubation periods of acute respiratory viral infections: a systematic review. Lancet Infect Dis. 2009;9(5):291-300.

18. Sjöström R, Söderström L, Klockmo C, Patrician A, Sandström T, Björklund G, et al. Qualitative identification and characterisation of self-reported symptoms arising in humans during experimental exposure to cold air. Int $J$ Circumpolar Health. 2019;78(1):1583528. 